\title{
What is life? Are viruses living entities?
}

\author{
Jaime Gómez-Márquez \\ Department of Biochemistry and Molecular Biology, \\ Faculty of Biology - CIBUS, University of Santiago de Compostela, \\ 15782 Santiago de Compostela, Galicia, Spain \\ e-mail: jaime.gomez.marquez@usc.es
}

\begin{abstract}
Summary
What is life, what is the difference between something that is alive and something that is not, are viruses living beings, or what would life be like elsewhere in the universe, are questions that still do not have clear-cut answers fully accepted by the scientific community. Based on the fundamental attributes of all living things, I define life as a process that takes place in very ordered organic structures and is characterized by being automatic, interactive and evolutionary. I also define a living being as an organic, highly ordered, automatic, interacting and evolutionary system, and a robot as an ordered automatic and interacting system. Based on this definition and what we know about the biology of viruses, I maintain that they should be considered as living entities. Finally, I explain why if there were life elsewhere in the universe, it would be very similar to what we know on our planet.
\end{abstract}

Keywords: life definition, living being definition, robot definition, living viruses, extraterrestrial life 


\section{Introduction}

In a previous work I have proposed what I call the seven commandments of life as a set of principles intrinsic to biology that together with the laws of physics and chemistry help us to understand the vital phenomenon. ${ }^{1}$ The commandments might represent in some way the foundation for building a scientific theory of life. Once we have an adequate theoretical support we can pose the answer to the great questions of biology: What is life? How did life originate? Are viruses living beings? How can we understand the evolutionary process? How the ecosystems evolve? Is there life on other planets? Etcetera. In this paper I focus my reflections on two questions in biology related to the definition of life as well as the consideration of viruses as living entities rather than lifeless particles.

From a conceptual point of view it is not so easy to establish the differences between the living and the non-living although, paradoxically, it is not too difficult to distinguish them. Thus we all know that a butterfly or an orchid is a living thing and that a stone or a piece of plastic is not. We can define life as the condition that is only present in living organisms but with this definition we do not adequately answer this question since it only expresses obviousness. All the proposed definitions that have attracted the attention of scientists and philosophers have been refuted with apparently robust counter-examples. ${ }^{2,3}$ There are even scientists and philosophers of science who believe that it is not possible to define what life is. ${ }^{3-5}$ However, I believe that it should be possible to define life if we apply the right strategy to do so.

\section{What is life?}

There are many definitions of life that were formulated based on different approaches (thermodynamic, evolutionary, metabolic, ecosystemic and autopoietic). ${ }^{6}$ It is worth noting the definition of life extracted from the vocabulary of definitions by Trifonov: "Life is self-reproduction with variations". T This short definition of life is very powerful because of its brevity and because it includes two fundamental characteristics of vital phenomena: reproduction and evolution. Along these lines, there is also the definition previously coined by NASA following a suggestion by C. Sagan: "Life is a self-sustaining chemical system capable of Darwinian evolution". 8,9 In my opinion this is also a good definition because it incorporates reproduction, evolution, metabolism and other biochemical processes. However, I consider that both definitions are not fully satisfactory because neither the cells nor the multicellular beings are completely self-sufficient; there is always a dependence on other organisms and external factors to live and reproduce. Furthermore, both definitions also say nothing about the chemical nature of living matter, 
interactions with the environment or the low entropy of living beings. A third example is a more recent definition of life, "Life is a far from equilibrium self-maintaining chemical system capable of processing, transforming and accumulating information acquired from the environment". ${ }^{10}$ In my opinion, this definition has three drawbacks: i) the term "self" should disappear because the quality of life does not provide self-sufficiency; ii) the thermodynamic component does not highlight how fundamental low entropy or high order is for any living being; iii) information can be acquired from "within" and not only from the environment. There are many more definitions of life but as R. Popa says "We may never agree on a definition of life, which will remain forever subject to a personal perspective". ${ }^{11}$

Some scientists and philosophers maintain that life cannot be defined from the attributes that we observe in living beings, but I believe that it is possible to do so, the key is to choose correctly the attributes that allow us to define without ambiguity what life is. What do viruses, bacteria, yeasts, lichens, trees, jellyfish, turtles, birds or whales have in common that clearly differentiates them from non-living systems? I think every living being has several unquestionable attributes: it is organic, it is order, it is automatism, it is interaction, it is reproduction and it is evolution. It is organic because the biochemistry of living things is based on the chemistry of carbon. It is order because living organisms are highly ordered structures that need energy to maintain it. It is automatism because there is a physical-chemical determinism in many structures and processes, ${ }^{1}$ and a genetic program that directs the development and functioning of every living being. It is a multi-interactive task because every organism interacts with itself, with other life forms and with its abiotic environment. We can see interactions at the molecular/cellular level (e.g. allosteric interactions, cell signalling, quorum sensing), in the communication between organisms (e.g., sexual reproduction, pollination, or sound language), or between living forms and the environment (e.g. photosynthesis or physiological interactions to swim or to fly). From the automatism and the multiple interactions arise the metabolism, physiology and the processes that capture and transform energy. Life is reproduction because it is the only way to defeat the second law of thermodynamics and the tyranny of time, generating a new vital order and, therefore, continuing its existence. ${ }^{1}$ Reproduction that is the only thing that ensures the continuity of each of the species. Finally, life is evolution (reproduction with variations) and this property is exclusive to life. Evolution allows living beings to adapt to new circumstances and thus life is perpetuated through time. So how can we define life from this set of attributes? The answer is combining them (Figure 1). According to this, I define life as a process that takes place in very ordered organic structures and is 
characterized by being automatic, interactive and evolutionary. What is the difference between life and being a living being? Life is the vital process and the living being is the system, the "container", where the vital process takes place. Therefore a living being is an organic, highly ordered, automatic, interacting and evolutionary system. In nature we can find many different living beings but all of them, one way or another, must comply with those attributes. Talking about artificial life, I will define a robot as an ordered automatic and interacting system. A robot is not something alive because is neither organic nor has the capacity to evolve.

From this definition of life, could we consider as a living being an organism that is sterile and therefore unable to evolve? Of course it is a living being because is "an organic ordered automatic and interacting system" but since it is sterile it has lost the capacity to evolve, is a biological death end. This is similar to what Benner wrote "one rabbit may be alive even though he or she is not life". ${ }^{9}$ In any case, we have to look at the evolutionary process at the population level, not at the level of individual organisms; if an individual is sterile it will not be able to pass on its genes to its offspring but the species will continue to exist, but if the whole population were sterile, then the species would disappear and there would be no life.

\section{Are the viruses living things?}

Whether or not viruses are alive has been controversial. ${ }^{12}$ Some scientists consider viruses as living beings and classify them as capsid-encoding organisms, in contrast to the ribosome-encoding organisms that include all cellular life forms. ${ }^{13}$ There are scientists in the opposite side and do not consider viruses as living entities because their inability to reproduce in the absence of a cellular host. ${ }^{14}$ Furthermore, I disagree with their consideration as non-living creatures because they need a cell to reproduce for two simple reasons: i) viruses are parasites and like all parasites use the host for their own benefit (their survival strategy); ii) all cells and organisms also need "something" to reproduce because none living creature is self-sustaining since, at least, it needs an energy supply for reproduction and this energetic supply comes from their environment. We could take the argument that viruses need a cell to reproduce and therefore are not living beings to the absurd and say that a man or a woman are not living beings because by themselves they would be sterile. Nonetheless, for a growing number of biologists, viruses have to be considered as living beings for two main reasons: they contain proteins and nucleic acids and they have the capacity of evolving. ${ }^{15}$ Other authors justify the living nature of viruses 
in their fundamental role in evolution and argue that they should be seen as processes rather than things or substances. ${ }^{16}$

I consider viruses to be living entities for four reasons that are contained within my definition of life (Figure 2). Firstly, a virus is composed of a nucleic acid (DNA or RNA), which constitutes its genetic material as with any living being; the viral genetic material is protected by a protein capsule that is also involved in the propagation of the viral genome. Secondly, viruses are highly ordered structures and both in their assembly and in their ability to infect the host cell they demonstrate an automatism perfected through millions of years of evolution. Many viruses have developed a very successful self-assembly system; so much so that the viral capsid can self-assemble even outside the host cell. ${ }^{17}$ Thirdly, viruses form part of many integrated biological systems and processes and they played an important role in the evolution of species. ${ }^{18}$ Viruses are intracellular parasites that interact with the host thru infection and reproduction and/or latency. Viruses interact with the host by exchanging genetic material and also participating in horizontal gene transfer ${ }^{19}$ and may jump from one individual of one species to another of a different species. ${ }^{20}$ Fourthly, since viruses have their own genome and this genetic material can mutate, these microorganisms have the capacity to evolve and this is a fundamental characteristic of all vital phenomena. Due to their high frequency of mutation ${ }^{21}$, viruses are so abundant in nature and present such a high degree of diversity that they constitute by themselves what some have called the virosphere. ${ }^{22}$ This great viral biodiversity is proof that these living entities perform fundamental evolutionary and ecological functions. ${ }^{23,24}$

\section{What would life be elsewhere in the universe?}

Is there life elsewhere in the universe? Astrobiologists are committed to the search for life in the Cosmos and for that purpose it is very convenient to have a criterion about what life is. ${ }^{9}$ I believe we have to have an open mind in the search for life outside our planet, but at the same time I think it is a good idea to have a hypothesis that helps in the design of the search for extraterrestrial life.

It is probably only a matter of time before we find life on other planets or aliens find us. In my opinion if there is life elsewhere in the universe, it will most likely be similar to what existed, exists or will exist on our planet. Let us see why. First of all, the laws of physics and chemistry are universal and these laws, directly or indirectly, govern everything that happens in the matter of the universe; living matter in addition to these laws has its own rules that I call the commandments. ${ }^{1}$ Second, the elements that make up the matter of the stars are the same everywhere in the universe although in different 
proportions; the "periodic table" is the same for the whole universe. Third, the inexorability principle (the $2^{\text {nd }}$ commandment) that states "life is like that because it should be like that". ${ }^{1}$ What does it mean? It means that if the environmental conditions are right, glucose will be converted into pyruvate in an aqueous medium, flying organisms will have wings, or genetic information will be encoded in a language analogous or identical to what we know on Earth. According to this the differences between the Earth living forms and the "space creatures" could be attributed to a different evolutionary stage or to specific environmental conditions (Figure 3).

\section{DECLARATIONS:}

Funding: No funding supported this work.

Conflicts of interest: No conflicts or competing interests

Acknowledgements: I would like to thank all those people who believed that my ideas could be useful for Biology, especially to my colleagues ML González Caamaño and R Anadón,. This work is dedicated to my parents. 


\section{REFERENCES:}

1. Gómez-Márquez, J. (2020) What are the principles that govern life? Commun Integr Biol. 13, 97-107.

2. Cleland, C. E., Chyba, C. F. (2002) Defining “life”. Orig Life Evol Biosph. 32, 387-392.

3. Cleland, C. E. (2019) The Quest for a Universal Theory of Life. Cambridge University Press, Cambridge.

4. Cleland, C. E. (2011) Life without definitions. Synthese 185, 125-144.

5. Koonin, E. V. (2012) Defining Life: an exercise in semantics or a route to biological insights? J Biomol Struct Dyn. 29, 603-605.

6. Luisi, P. L. (1998) About various definitions of life. Orig Life Evol Biosph. 28, 613-622.

7. Trifonov, E. N. (2011) Vocabulary of definitions of life suggests a definition. J Biomol Struct Dyn. 29, 259-266.

8. Joyce, G. F. (1994) Forward. In Origins of life: the central concepts (Deamer, D.W., Fleischaker GR, eds.), Jones \& Bartlett, Burlington.

9. Benner, S. A. (2010) Defining life. Astrobiology 10, 1021-1030.

10. Vitas, M., Dobovišek, A. (2019) Towards a general definition of life. Orig Life Evol Biosph. 49, 77-88.

11. Popa, R. (2012) Merits and caveats of using a vocabulary approach to define life. J Biomol Struct Dyn. 29, 607-608.

12. Koonin, E. V., Starokadomskyy, P. (2016) Are viruses alive? The replicator paradigm sheds decisive light on an old misguided question. Stud Hist Philos Biol Biomed Sci. 59, 125-134.

13. Raoult, D., Forterre, P- (2008) Redefining viruses: lessons from mimivirus. Nature Rev Microbiol. 6, 315-319.

14. Moreira, D., López-García, P. (2009) Ten reasons to exclude viruses from the tree of life. Nature Rev Microbiol. 7, 306-311.

15. Forterre, P. (2010) Defining life: the virus viewpoint. Orig Life Evol Biosph. 40, 151-160.

16. Dupré, J., Guttinger, S. (2016) Viruses as living processes. Stud Hist Philos Biol Biomed Sci. 59, 109-116.

17. Baschek, J. E., Klein, H., Schwarz, U. S. (2012) Stochastic dynamics of virus capsid formation: direct versus hierarchical self-assembly. BMC Biophysics 5, 22-40.

18. Koonin, E. V., Dolja, V. V. (2013) A virocentric perspective on the evolution of life. Curr Opin Virol. 3, 546-557.

19. Forterre, P. (2010) Giant viruses: conflicts in revisiting the virus concept. Intervirology 53, 
$362-378$.

20. Faria, N., Suchard, M. A., Rambaut, A., Streicker, D. G., Lemey, P. (2013)

Simultaneously reconstructing viral cross-species transmission history and identifying the underlying constraints. Phil Trans $R$ Soc B. 368, 20120196.

21. Duffy, S. (2018) Why are RNA virus mutation rates so damn high? PLoS Biol. 16: e3000003

22. Zhang, Y.-Z., Shi. M., Holmes. E. C. (2018) Using metagenomics to characterize and expanding Virosphere. Cell 172, 1168-1172.

23. Rohwer, F., Prangishvili, D., Lindell, D. (2009) Roles of viruses in the environment. Environ. Microbiol. 11, 2771-2774.

24. O’Malley, M. A. (2016) The Ecological virus. Stud Hist Philos Biol Sci. 59, 71-79.

\section{Legends to Figures}

Figure 1. What is life? It is shown how the combination of the attributes of living beings leads to the definition of life, living beings and robots.

Figure 2. Viruses as living entities. This diagram shows the characteristics and attributes that allow viruses to be considered as living beings.

Figure 3. Life elsewhere in the universe. To answer the question that heads this figure, I take into consideration four basic factors: living beings attributes, life commandments, the matter of universe and the laws of physics and chemistry. The conclusion is that if there is life elsewhere in the universe it would be very similar to what we know on Earth. 


\section{What is Life?}

\section{Living Beings Attributes}

\begin{tabular}{|l|l|l|l|l|}
\hline Organic & Order & Automatism & Interaction & Reproduction \\
\hline
\end{tabular}
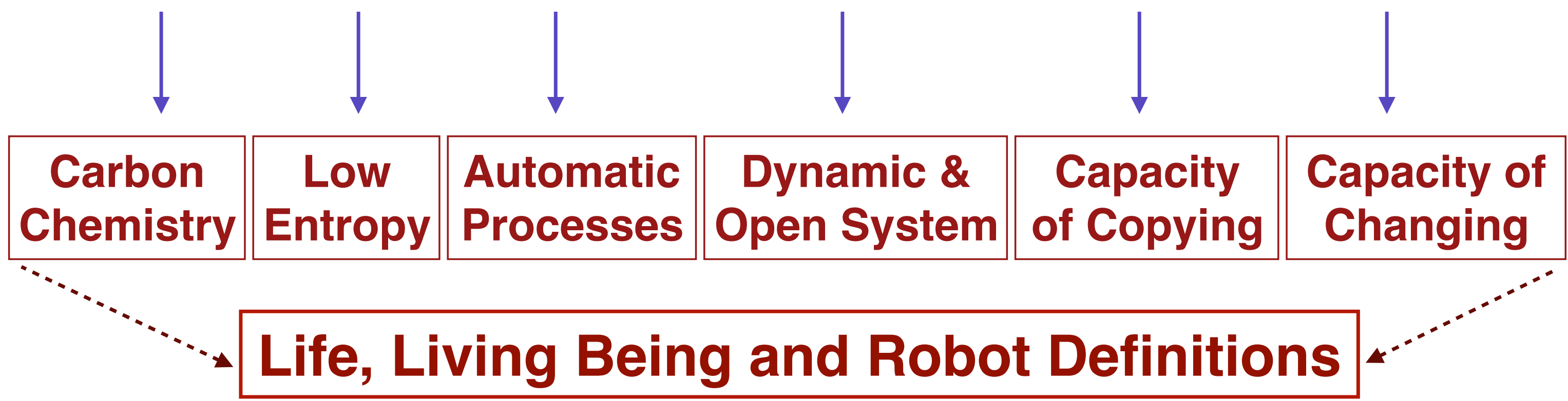

Life is a process that takes place in very ordered organic structures and is characterized by being automatic, interactive and evolutionary. Life is the vital process

A living being is an organic, highly ordered, automatic, interactive and evolutionary system. The living being is the "container" where the vital process occurs

A robot is an ordered automatic and interactive system. It is a lifeless engine 


\section{Why are viruses living entities?}

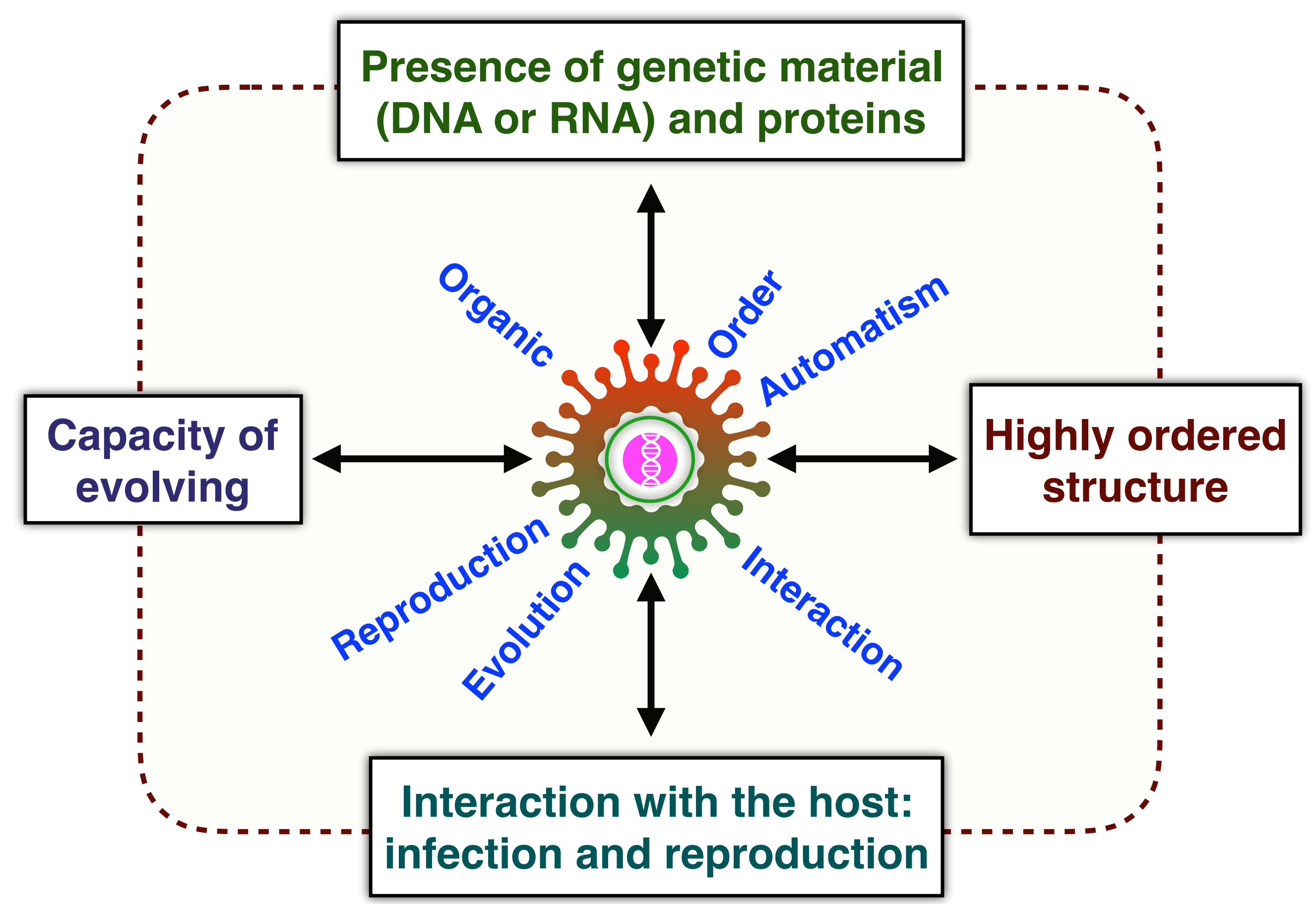




\section{What would life be like elsewhere in the universe?}
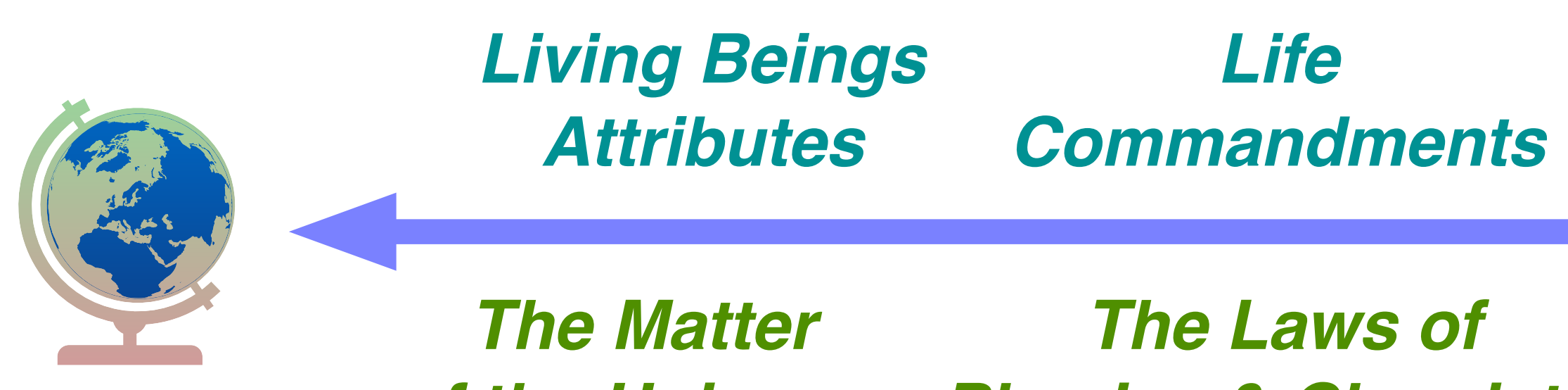

The Matter

The Laws of of the Universe Physics \& Chemistry

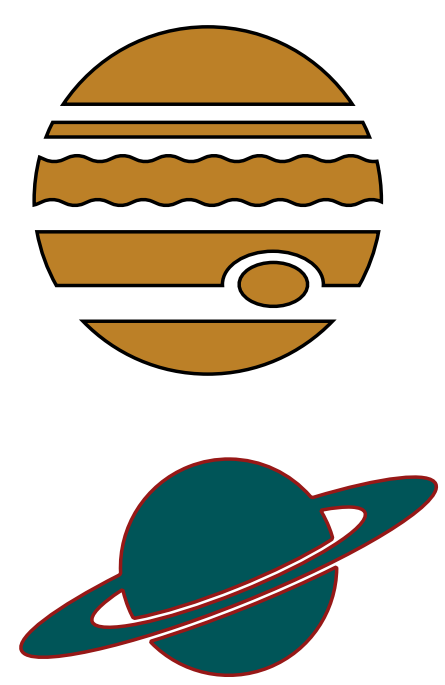

It would be very similar to what we know on Earth

The differences we might find would be due to organisms being in another evolutionary stage, to particular environmental conditions, or both 